\title{
Thermal Control Design Conception of the Amazonia-1 Satellite
}

\author{
Douglas Felipe da Silva', Issamu Muraoka', Ezio Castejon Garcia²
}

\begin{abstract}
Amazonia-1 is a Brazilian remote sensing satellite providing mainly images, in order to observe and monitor deforestation, especially in the Amazon region. This paper describes the thermal control design, which uses passive and active concepts. The active thermal control is based on heaters regulated by software via thermistors. The passive thermal control consists of multi-layer insulation blankets and radiators, paints, surface finishes to maintain temperature level of the overall carrier components within an acceptable value. The thermal control design is supported by thermal analysis using thermal mathematical model. The temperatures and heater power are predicted for critical cases.
\end{abstract}

KEYWORDS: Amazonia-1 satellite, Satellite thermal control, Thermal mathematical model.

\section{INTRODUCTION}

The Amazonia-1 Thermal Control Subsystem (TCS) consists of active and passive thermal control elements in order to maintain the spacecraft's components and structure within a controlled range of temperature throughout the mission of the spacecraft, from the Beginning of Life (BOL) to the End of Life (EOL). The payload equipment, the propulsion subsystem components and batteries, along with their operational requirements, are the main drive to develop Amazonia-1 thermal control design and analysis.

The Amazonia-1 mission's main goal is to provide image data, improving the deforestation monitoring capability in the Amazon region. The use of a new instrument called Advanced Wide Field Imager (AWFI) with a 40-meter spatial resolution on board will improve the capability of the system (Scaduto et al., 2010). The current Wide Field Imager (WFI) camera acquires images in two spectral bands, while in the AWFI the images will be acquired in four bands. Figure 1 presents the satellite.

The remote sensing Amazonia-1 satellite is the first mission to use the Multi-Mission Platform (MMP) concept developed by the Instituto Nacional de Pesquisas Espaciais (INPE), coordinated

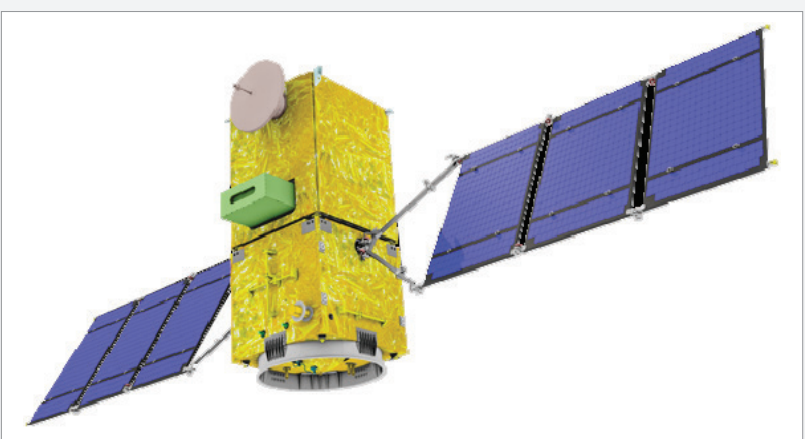

Figure 1. Amazonia-1 satellite.

\footnotetext{
三 1. Instituto Nacional de Pesquisas Espaciais - São José dos Campos/ SP - Brasil 2. Instituto Tecnológico de Aeronáutica - São José dos Campos/ SP - Brazil Author for correspondence: Douglas Felipe da Silva | Instituto Nacional de Pesquisas Espaciais - Av. dos Astronautas, 1.758, São José dos Campos/SP | CEP: 12.227-010 | Brazil | Email: douglas.silva@inpe.br

Received: 01/13/2014 | Accepted: 04/17/2014
} 
by Brazilian Space Agency (AEB). The MMP platform concept provides capability to support a variety of low Earth orbit missions using the same basic three-axis stabilized platform, with different payload instruments (Santana et al., 2012). The MMP main design goal is modularity, allowing separated integration from the satellite payload module. This provides independent design, construction and test of each module before payloadto-MMP integration and final compatibility tests.

There is an extended amount of works available in the literature about satellite thermal control and, for instance, the handbook of Gilmore (2002), as well as the text books of Karam (1998) and Messeguer et al. (2012), are some of the best work presented.

\section{FEATURES OF THE AMAZONIA-1 SATELLITE}

A few salient features of Amazonia-1 satellite are as follows:

- Overall dimensions of the main body: 2,200 x 950 x 950 mm;

- Mass: About $500.0 \mathrm{~kg}$;

- Orbit: Sun-synchronous, $752.4 \mathrm{~km}$ high, $98.405^{\circ}$ inclination and passage time 10:30 a.m.;

- Structure: Aluminum honeycomb structure;

- Power: $420 \mathrm{~W}$ (average), InGAP/InGaAs/Ge solar panels, lithium ion battery;

- Stabilization: 3 axis stabilized;

- Mission life: 4 years.

The exploded view of the MMP is presented in Fig. 2, and Fig. 3 presents the payload.

During nominal operation mode, the - $\mathrm{Y}$ face will be always pointed to Earth. In emergency mode, the satellite attitude control will point $-Z$, facing the Sun, in order to warm up the propulsion subsystem elements, and two rotations per orbit will be imposed around the $\mathrm{Z}$ axis (in negative direction), in order to distribute external heat loads equally on the lateral panels.

\section{CONSTRAINTS AND REQUIREMENTS TO TCS}

The Amazonia-1 TCS shall provide a thermal environment which ensures reliable performance of all components during all mission

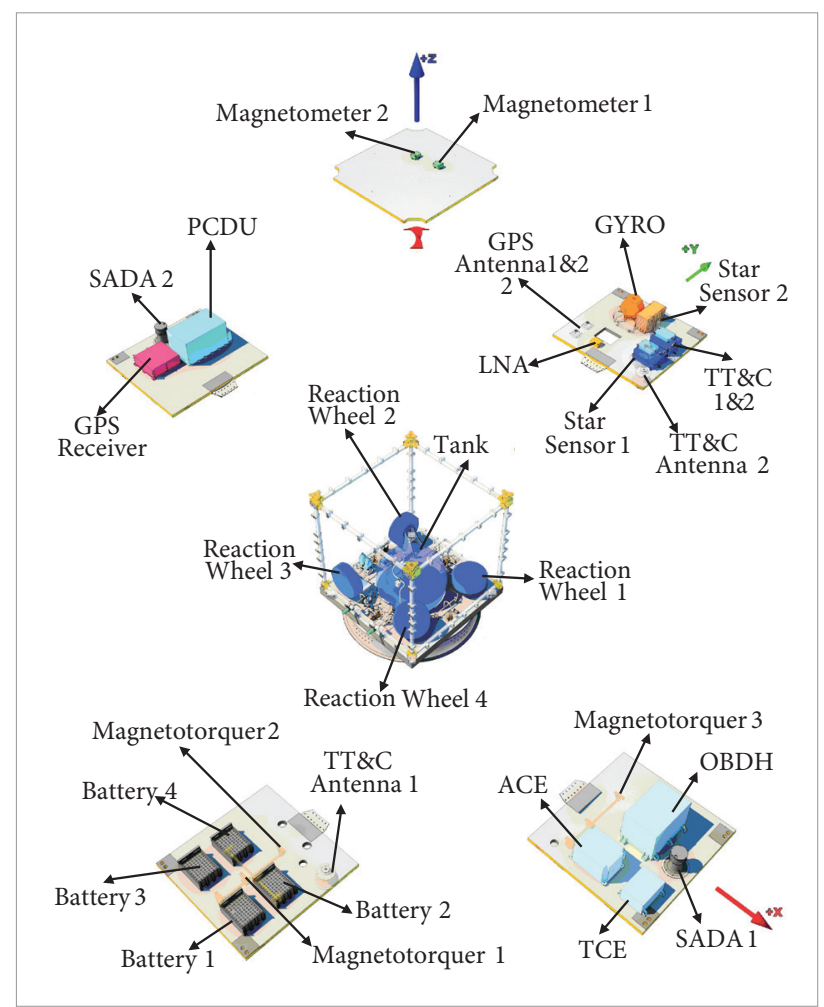

Figure 2. Exploded view of the MMP.

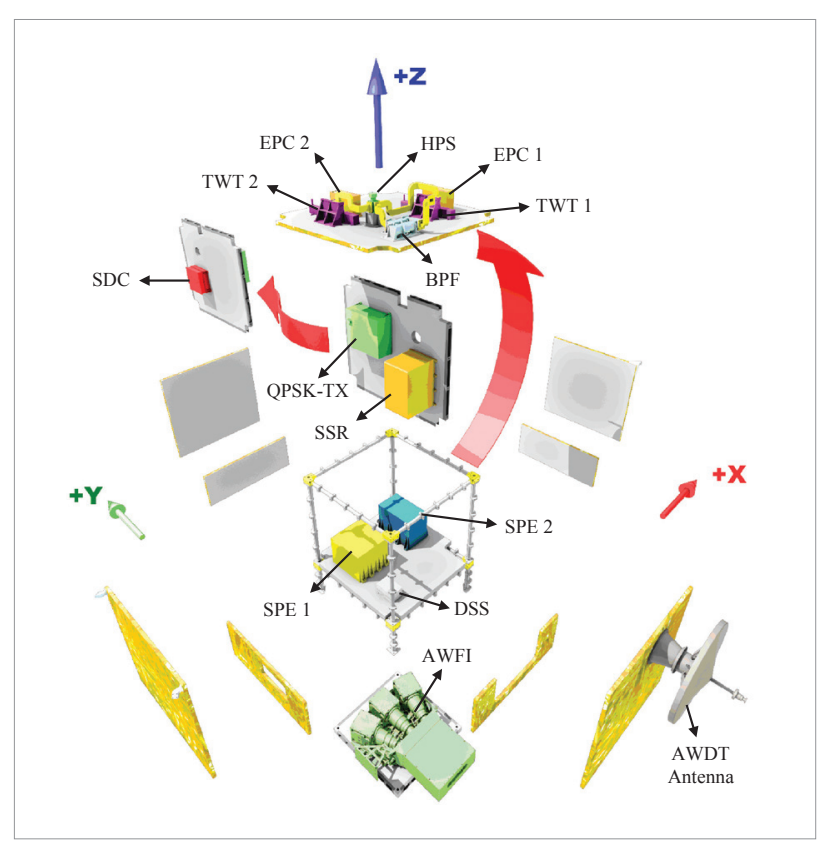

Figure 3. Exploded view of the payload.

phases, minimizing the thermal control mass and heater power budgets. The main functions of the Amazonia-1 thermal control are: 
- To provide temperature distribution in order to have all onboard equipment operate within their designed operational temperature range, under all possible attitudes experienced during all mission phases;

- To allow the dissipation of the excess energy generated with no detrimental effect.

The Amazonia-1 thermal design conception is based on the balance of the following criteria:

- Insulate, as well as possible, the satellite of external environment. Making use of this approach, temperatures are less sensitive to the external radiation and the satellite can perform better during all mission stages. Radiators are used in order to reject internal heat dissipation;

- Minimization of thermal gradients in the satellite by using high emittance coatings on the majority of the internal surfaces (equipment and structural parts) and improving the conductive coupling between equipment and mounting panels, through thermal interface filler materials;

- For AWFI, batteries and propulsion components, which have operational temperature limits quite different from the remaining equipment in the satellite, the paragraph above is not applicable. These components shall be thermally insulated - by radiation and conduction - from the satellite, having their temperatures controlled individually by heaters;

- Insulate the equipment placed in direct view to space from the space environment. This is necessary in order to avoid large temperature fluctuation on these equipment, through illuminated and eclipse periods;

- Insulate MMP from payload module, considering the premise that the MMP is a multi-mission platform and its thermal design shall be qualified for any payload;

- The electrical power allowance for heaters shall not exceed $30 \mathrm{~W}$ during mission nominal modes and $60 \mathrm{~W}$ during emergency mode;

- The temperature limits (operational and non-operational) and the heat dissipation for all equipment are disposed in Table 1 (payload) and Table 2 (MMP). The cases in these tables will be described further on in "Cases under evaluation".

\section{THERMAL CONTROL SYSTEM USED IN AMAZONIA-1}

As explained before, in order to minimize temperature gradients, all internal surfaces of the satellite are coated with

Table 1. Payload equipment temperature limits and heat dissipation.

\begin{tabular}{|c|c|c|c|c|}
\hline \multirow{2}{*}{ Equipment } & \multirow{2}{*}{ Temperature Range $\left({ }^{\circ} \mathbf{C}\right]$} & \multicolumn{3}{|c|}{ Heat Dissipation (W) } \\
\hline & & Case A & Case B & Case C \\
\hline AWDT Antenna & $-100 \sim 80$ & 0 & 0 & 0 \\
\hline BPF & $-30 \sim 60$ & 0 & 0 & $10.0^{(1)}$ \\
\hline DSS & $-10 \sim 45(-20 \sim 55)^{(2)}$ & 0 & 3.0 & 3.0 \\
\hline $\operatorname{EPC}(x 2)$ & $-20 \sim 60(-30 \sim 75)^{(2)}$ & 0 & 0.1 & $1.5^{(3)}$ \\
\hline HPS & $-20 \sim 50(-30 \sim 60)^{(2)}$ & 0 & 0 & $3.2^{(1)}$ \\
\hline QPSK-TX & $-10 \sim 45(-20 \sim 50)^{(2)}$ & 0 & 0 & $12.0^{(1)}$ \\
\hline SDC & $-10 \sim 45(-20 \sim 55)^{(2)}$ & 0 & 0 & $4.0^{(1)}$ \\
\hline SPE1 & $-10 \sim 45$ & 6.0 & 6.0 & $90.9^{(4)}$ \\
\hline SPE2 & $-10 \sim 45$ & 22.1 & 22.1 & $101.6^{(4)}$ \\
\hline SSR & $-10 \sim 45(-20 \sim 55)^{(2)}$ & 0 & 5.0 & 10.0 \\
\hline TWT (x2) & $-20 \sim 60(-30 \sim 75)^{(2)}$ & 0 & 0 & $40^{(3)}$ \\
\hline
\end{tabular}

(1)15 min of operation in illuminated period; (2) non-operational temperature range; (3)15 min of operation in illuminated period (only main unit; the redundant one is on stand-by]; ${ }^{(4)} 25 \mathrm{~min}$ of operation in illuminated period. 
high emittance black paint. All external surfaces are wrapped with 20 layers of Multilayer Insulation (MLI) blankets with areas available for positioning the radiators. In order to reduce heater power consumption during emergency mode, the internal face of the adapter cylinder, positioned at the MMP -Z panel, is kept in bare aluminum, as well as the areas of the $-\mathrm{Z}$ panel which are out of the cylinder circle.

The propulsion components were dealt with different approach since they shall be kept at a temperature range from $+10{ }^{\circ} \mathrm{C}$ to $+50{ }^{\circ} \mathrm{C}$. The lower limit of $+10^{\circ} \mathrm{C}$ is so to avoid hydrazine freezing. Considering that the lower temperature limit of the propulsion subsystem is considerably higher than those of the remainder MMP components, the thermal design was set according to the following baseline:

- Radiative insulation of all components (except thrusters) wrapping them with 15 layers of MLI blanket;
- Conductive insulation of all attachment points with the mounting panel using fiber glass-epoxy composite washer;

- Electrical heating using skin and spiral heaters on all components.

A total of seven heater circuits (four main and three redundant ones) are installed on the propulsion components, using correspondently 7 switched heater lines. All lines are controlled by ON/OFF commands from the On Board Data Handling $(\mathrm{OBDH})$, which uses the thermistor telemetry as input data. The thermistors which will be used are space qualified, interchangeable, NTC type with a resistance of $10 \mathrm{k} \Omega$ at $25^{\circ} \mathrm{C}$, and manufactured by Measurement Specialties ${ }^{\mathrm{TM}}$.

The batteries panel also received specific design since their range, 0 to $20^{\circ} \mathrm{C}$, is narrower than most of the electronic equipment in the satellite $\left(-10^{\circ} \mathrm{C} \sim 45^{\circ} \mathrm{C}\right)$. The concept is to couple the battery packs to the mounting panel and to use

Table 2. MMP equipment temperature limits and heat dissipation.

\begin{tabular}{|c|c|c|c|c|}
\hline \multirow{2}{*}{ Equipment } & \multirow{2}{*}{ Temperature Range $\left({ }^{\circ} \mathbf{C}\right.$ ] } & \multicolumn{3}{|c|}{ Heat Dissipation (W) } \\
\hline & & Case A & Case B & Case C \\
\hline ACE & $-10 \sim 45$ & 18.0 & 14.0 & 20.0 \\
\hline Battery (x4) & $-10 \sim 20^{(1)}$ & 2.3 & 2.3 & 2.8 \\
\hline GPS Antenna (x2) & $-20 \sim 55(-20 \sim 60)^{(2)}$ & 0 & 0 & 0 \\
\hline GYRO Elect. Module & $-20 \sim 60(-40 \sim 75)^{(2)}$ & 0 & 21.6 & 30.0 \\
\hline GYRO ICU & $-20 \sim 60(-40 \sim 75)^{(2)}$ & 0 & 0.1 & 0.2 \\
\hline LNA & $-10 \sim 45(-20 \sim 50)^{(2)}$ & 0 & 0.6 & 0.6 \\
\hline Magnetometer (x2) & $-20 \sim 50$ & 0 & 0 & 0 \\
\hline Magnetotorquer (x3) & $-10 \sim 50$ & 2.7 & 0 & 2.7 \\
\hline $\mathrm{OBDH}$ & $-10 \sim 45$ & 47 & 47 & 47 \\
\hline PCDU & $-10 \sim 45$ & 6.3 & 6.3 & $31.8^{(3)}$ \\
\hline Propulsion Elements & $+10 \sim 50$ & 0 & 0 & 0 \\
\hline Reaction Wheels (x4) & $-15 \sim 55$ & 6.7 & 6.7 & $40.4^{(4)}$ \\
\hline SADA (x2) & $-20 \sim 60$ & 4.6 & 5.1 & 6.5 \\
\hline Star Sensor (x2) & $-20 \sim 50(-40 \sim 70)^{(2)}$ & 0 & 0.2 & 13.5 \\
\hline TCE & $-10 \sim 45(-25 \sim 45)^{(2)}$ & 0 & 0 & 0.8 \\
\hline TT\&C (x2) & $-20 \sim 50$ & 6.2 & 6.2 & $14.6^{(5)}$ \\
\hline TT\&C Antenna (x2) & $-80 \sim 55$ & 0 & 0 & 0 \\
\hline
\end{tabular}

${ }^{(1)}$ At mounting panel; (2)Non-operational temperature range; ${ }^{(3)}$ Operation in illuminated period; ${ }^{(4)} 6$ min of operation in illuminated period; (5)15 min of operation in illuminated period (only main unit; the redundant one is on stand-by). 
this panel as a radiator. The mounting panel is insulated, conductively (through fiber glass-epoxy washers) and radiatively (15 layers of MLI blanket), from the other parts of the satellite.

In order to avoid the temperature at battery panels below $-10{ }^{\circ} \mathrm{C}$, heaters are placed at the panel, near the batteries' feet. The temperatures at the panel are monitored by four thermistors, placed near the heaters. The heater circuits will be activated by ON/OFF commands from the $\mathrm{OBDH}$. The main circuit will turn on at $-8{ }^{\circ} \mathrm{C}$ and turn off at $-6^{\circ} \mathrm{C}$, while the redundant ones will turn on at $-10^{\circ} \mathrm{C}$ and turn off at $-8{ }^{\circ} \mathrm{C}$. The temperature refers to the lowest value among the four thermistors.

The AWFI has autonomous thermal control, and it is wrapped with a MLI blanket and conductively insulated from the mounting panel through washers. Also, it has its own radiator and dedicated heaters. Since its thermal control is independent from the satellite (Scaduto et al., 2010), in this global analysis, its temperature was considered to be between $15^{\circ} \mathrm{C}$ and $20^{\circ} \mathrm{C}$.

The thermal optical properties of coatings used in the satellite are presented in Table 3.

\section{VERIFICATION OF DESIGN BY THERMAL MATHEMATICAL MODELING}

The thermal modeling is based on a nodal or lumped parameter method. In this method, the satellite is divided in a number of regions, assumed isothermal, which is called nodes. These nodes exchange heat among each other by conduction and radiation, and with space by radiation. Also, they can receive heat loads from external sources or from electronic components. The temperature of each node is the result of these interactions. The governing equation is the energy equation which consists of transient, conduction, and radiation terms, plus boundary conditions (solar radiation, albedo and Earth radiation), as a source term. This equation can be written as presented in Eq. (1) (Karam, 1998):

$(m c p)_{i} \frac{d T_{i}}{d t}=Q_{i}^{D}+\left(\alpha Q^{S}+\alpha Q^{A}+\varepsilon Q^{E}\right)_{i}-\sum_{j=1}^{n} K_{i j}\left(T_{i}-T_{j}\right)-\sum_{j=1}^{n} \sigma R_{i j}\left(T_{i}^{4}-T_{j}^{4}\right)$

Where the thermal mass is $m c p[\mathrm{~J} / \mathrm{K}]$. The external loads are $Q^{\mathrm{S}}, Q^{\mathrm{A}}$, and $Q^{\mathrm{E}}[\mathrm{W}]$, while internal heat dissipation is $Q^{\mathrm{D}}[\mathrm{W}]$. The conduction and radiation exchange factors are represented by $K_{\mathrm{ij}}[\mathrm{W} / \mathrm{K}]$ and $R_{\mathrm{ij}}\left[\mathrm{m}^{-2}\right]$, respectively. The Stefan-Boltzmann constant is $\sigma\left[\mathrm{W} / \mathrm{m}^{2} / \mathrm{K} 4\right]$, and $T_{\mathrm{i}}$ and $T_{\mathrm{j}}[\mathrm{K}]$ are the temperatures of nodes $i$ and $j$, respectively.

The temperatures have been calculated in transient regime, considering variations on external heat loads and equipment heat dissipation profiles. The model was built using the C\&R Technologies ThermalDesktop/Radcad - SINDA/FLUINT thermal software package, and details of this package can be obtained in Panczak et al. (1998).

The MMP is represented by 2,764 diffusion nodes and 1,698 arithmetic ones, while the payload is represented by 4,161 diffusion, 1,444 arithmetic and 2 boundary nodes. Thus, the whole model is composed by 6,925 diffusion nodes, 3,142 arithmetic nodes and 2 boundary ones (total of 10,069 nodes).

The arithmetic nodes are used in order to represent the MLI blankets, which have small mass, since these elements have very low thermal capacitances and respond almost instantaneously to the thermal changes of environment.

The boundary nodes are used in order to represent a component with constant temperature. In this case, the equipment is the AWFI, since it has its own active thermal control and it shall operate between $+15^{\circ} \mathrm{C}$ and $+20^{\circ} \mathrm{C}$.

Table 3. Coatings' thermal optical properties.

\begin{tabular}{|c|c|c|c|c|}
\hline \multirow{2}{*}{ Coating } & \multirow{2}{*}{ Emissivity $[\varepsilon]$} & \multicolumn{2}{|c|}{ Absorptivity $[\alpha]$} & \multirow{2}{*}{$\begin{array}{c}\text { Effective } \\
\text { Emissivity (zeff }\end{array}$} \\
\hline & & BOL & EOL & \\
\hline Bare Aluminum & 0.05 & 0.15 & 0.15 & - \\
\hline Black Paint & 0.88 & 0.95 & 0.95 & - \\
\hline MLI & 0.80 & 0.41 & 0.51 & 0.02 \\
\hline White Paint & $\begin{array}{l}0.94 \text { (BOL) } \\
0.95 \text { (EOL) }\end{array}$ & 0.20 & 0.33 & - \\
\hline
\end{tabular}




\section{CASES UNDER EVALUATION}

The design philosophy is to find the critical cases and analyze them supposing that all other cases result in intermediate temperatures. Three critical cases are evaluated: cold, hot and emergency cases.

- Case A: Cold case represents the nominal operational mode in which minimum external heat loads (albedo: 0.34; Earth radiation: $208 \mathrm{~W} / \mathrm{m}^{2}$; solar radiation: $\left.1326 \mathrm{~W} / \mathrm{m}^{2}\right)$, minimum internal heat dissipation and BOL optical properties are considered. The orbit parameters are adopted for winter solstice, and the satellite -Y face will be pointing towards Earth;

- Case B: Hot case represents the nominal operational mode in which maximum external heat loads (albedo: 0.42; Earth radiation: $233 \mathrm{~W} / \mathrm{m}^{2}$; solar radiation: $1418 \mathrm{~W} / \mathrm{m}^{2}$ ), maximum internal heat dissipation and EOL optical properties are considered. The orbit parameters are adopted for summer solstice, and the satellite -Y face will be pointing towards Earth;

- Case C: Emergency case represents the satellite with attitude different from the nominal mode. In this case, the satellite $-\mathrm{Z}$ face is permanently oriented towards the Sun and the solar panel is oriented parallel to the $-\mathrm{Z}$ panel. The spin rate is two revolutions per orbit around the $\mathrm{Z}$ axis, in negative direction. The power consumption is minimized in this mode. Some equipment are turned off during this case and the temperature limit is the non-operation limit. The external heat loads, orbit parameters and optical properties are the same considered in case A (nominal cold case).

\section{TEMPERATURES AND HEATERS POWER CONSUMPTION PREDICTIONS}

The temperatures have been calculated in transient condition, and the stabilization criterion was considered when the temperature variation between two consecutive orbits is less than $0.1{ }^{\circ} \mathrm{C}$ in the same orbit point, for hot case. In cold and emergency cases, it is not possible to accomplish this criterion, since heaters are required and their ON/OFF dynamic does not allow the same conditions at the same orbit point. In this case, a minimum of 15 orbits are simulated.

The extreme predicted temperatures for payload (minimum for emergency case and maximum for hot case) are shown in Fig. 4. By analyzing Fig. 4, it should be noted that the predicted range of the equipment are the extremes of the central (black solid) bar. The empty space between this bar and the other two ones (minimum limit to the left and maximum to the right) is the temperature margin of the equipment.

The extreme predicted temperatures for MMP are shown in Fig. 5.

All maximum temperatures were predicted with at least $5{ }^{\circ} \mathrm{C}$ of margin, and the cold ones are controlled by heaters. It should be noted that the predicted temperatures of the solar array generator exceeded the acceptable range $\left(-80^{\circ} \mathrm{C}\right.$ to $80^{\circ} \mathrm{C}$ ), reaching $-84.6{ }^{\circ} \mathrm{C}$ in the emergency case and $82.1^{\circ} \mathrm{C}$ in the hot case. Although its temperature does not affect the satellite thermal behavior considerably, a detailed thermal analysis will be accomplished in order to satisfy its temperature requirement.

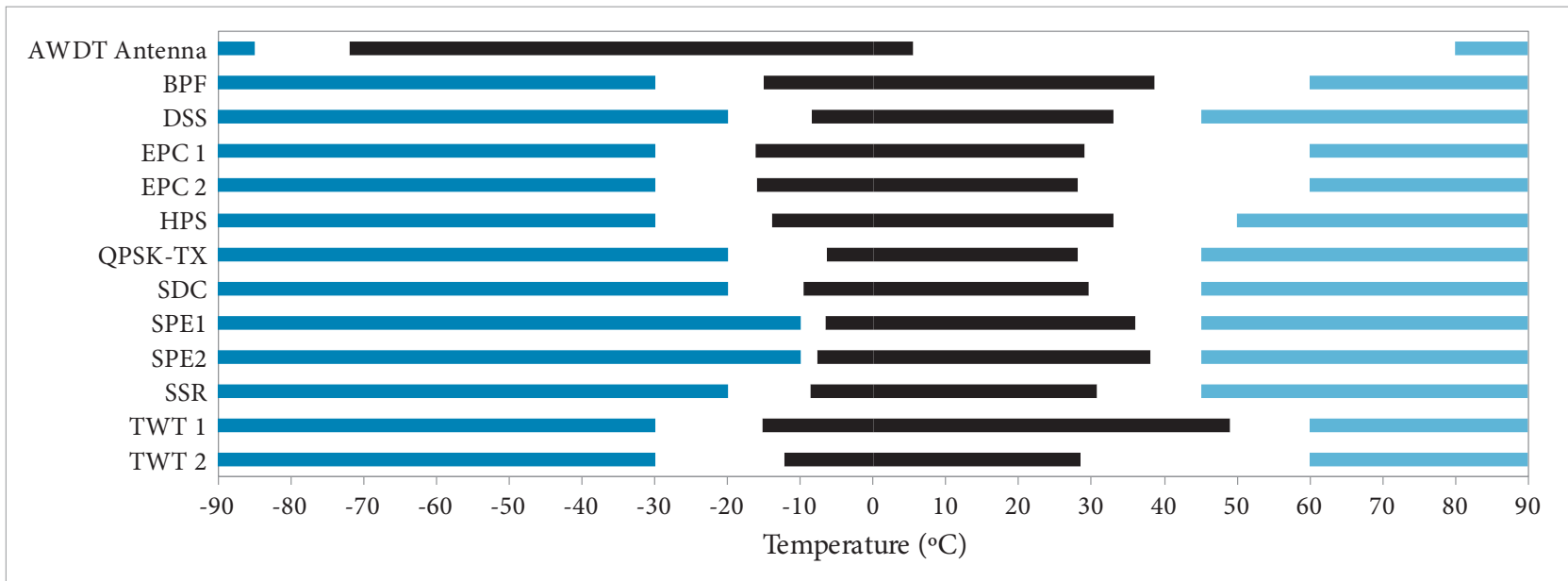

Figure 4. Payload predicted temperatures. 
To achieve the temperatures presented in Figs. 4 and 5, it was necessary to determine radiators areas. The process to find these areas, presented in Table 4 , is iterative.

The average power consumption for all heaters, during cold and emergency cases, is presented in Table 5.

For the nominal cold case (Case A), the heater power consumption is within the requirement $(30 \mathrm{~W})$ with $25 \%$ margin, according to U.S. Department of Defense (1982). For emergency cases, the predicted power does not comply with the requirement $(60 \mathrm{~W})$. This value is under review, since in emergency cases the overall power consumption is reduced and more power is available. The emergency case is thermally critical due to its distinct attitude, in which the payload module remains in the Sun shadow, and almost all equipment are turned off.

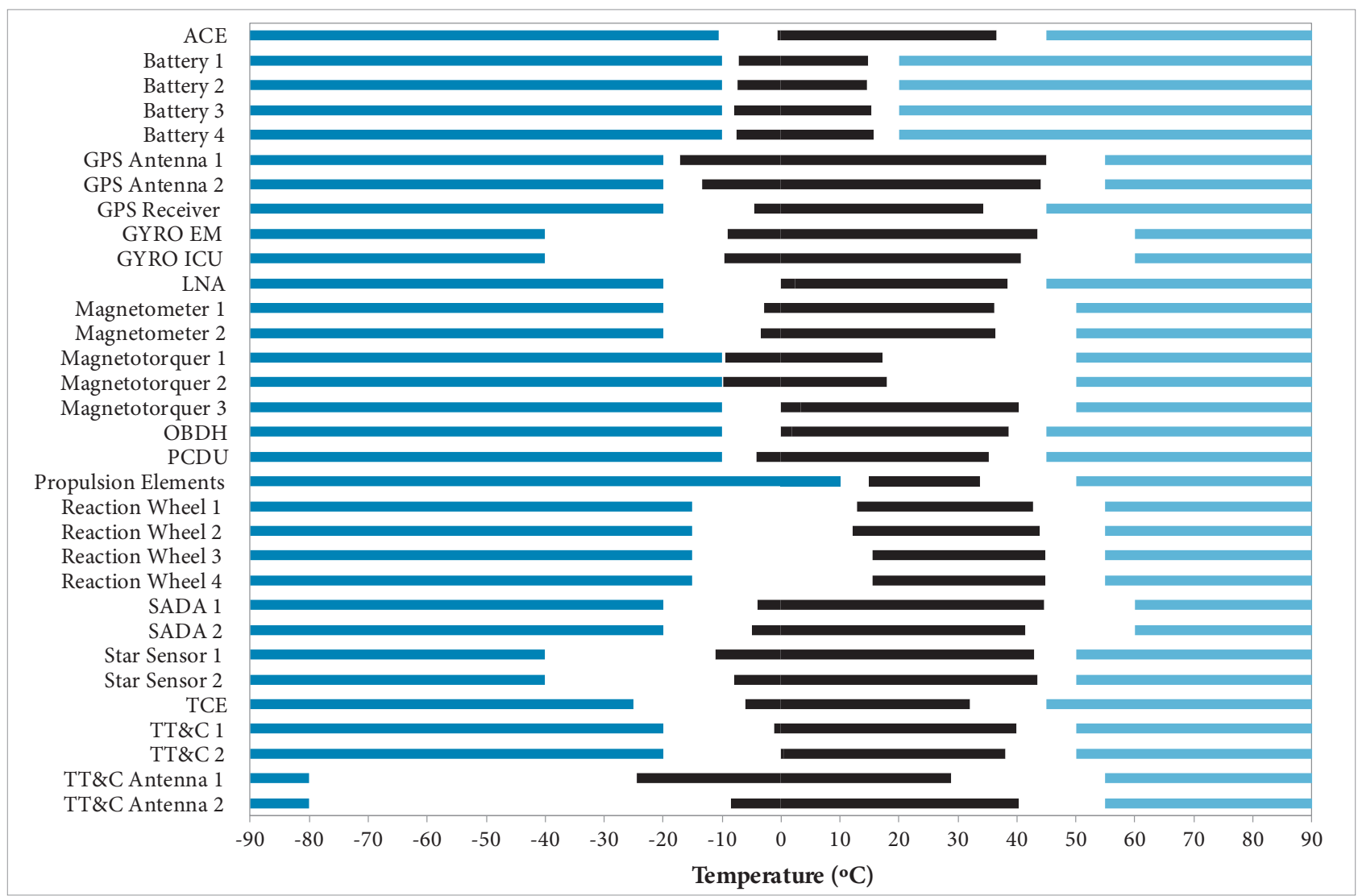

Figure 5. MMP predicted temperatures.

Table 4. Radiators areas.

\begin{tabular}{|c|c|c|}
\multirow{2}{*}{$\begin{array}{c}\text { Radiator } \\
\text { Location }\end{array}$} & \multicolumn{2}{|c|}{ Area $\left(\mathrm{m}^{2}\right)$} \\
\cline { 2 - 3 } & MMP & Payload \\
\hline +X Face & 0.3624 & 0.2356 \\
\hline -X Face & 0.1035 & 0.015 \\
\hline+ Y Face & 0.24 & 0.1596 \\
\hline -Y Face & 0.432 & 0 \\
\hline Total & 1.1379 & 0.4102 \\
\hline
\end{tabular}

Table 5. Heaters power consumption.

\begin{tabular}{|c|c|c|}
\hline \multirow{2}{*}{ Heater } & \multicolumn{2}{|c|}{ Power Consumption (W) } \\
\cline { 2 - 3 } & Case A & Case C \\
\hline $\begin{array}{c}\text { Batteries } \\
\text { Panel }\end{array}$ & 1.44 & 32.42 \\
\hline $\begin{array}{c}\text { Payload } \\
\text { Module }\end{array}$ & 12.45 & 44.37 \\
\hline $\begin{array}{c}\text { Propulsion } \\
\text { Elements }\end{array}$ & 3.69 & 2.85 \\
\hline Total & 17.58 & 79.64 \\
\hline
\end{tabular}




\section{CONCLUSIONS AND FUTURE ACTIONS}

The Amazonia-1 thermal control design and analysis were presented. This design has been verified through the use of the SINDA/FLUINT thermal analyzer, and established by using passive means and heaters. All subsystems have been in the specified temperature ranges, for nominal and emergency cases. The heater power predicted for nominal operational cases complies with the specification, however, in an emergency case, the predicted value is beyond specification. This requirement is under review and may possibly be increased.

A thermal model based in this design will be submitted to the Thermal Balance Test, in order to qualify the thermal design. Afterwards, the results will be correlated, and the thermal mathematical model validated.

\section{REFERENCES}

Gilmore, D.G., 2002, "Spacecraft Thermal Control Handbook", 2nd Edition, The Aerospace Corporation Press, El Segundo, CA, Vol. I.

Karam, R.D., 1998, "Satellite Thermal Control for System Engineers", Progress in Astronautics and Aeronautics, AIAA, Cambridge, Vol. 181, pp. 274.

Meseguer, J., Pérez-Grande, I. and Sanz-Adréz, A., 2012, "Spacecraft Thermal Control", Woodhead Publishing, Cambridge.

Panczak, T., Ring, S. and Welch, M., 1997, "A CAD-based Tool for FDM and FEM Radiation and Conduction Modeling", Cullimore and Ring Technologies, 28th ICES Conference, SAE Paper 981577.

Santana, A.C., Martins-Filho, L.S., Duarte, R.O., Arantes Jr., G. and Casella, I.S., 2012, "Attitude Control of a Satellite by Using Digital Signal
Processing", Journal of Aerospace Technology and Management, Vol. 4, No. 1, pp. 15-24. doi: 10.5028/jatm.2012.04014611.

Scaduto, L.C.N., Carvalho, E.G., Santos, A.R., Soares, A.L., Castellar, A., Azeka, L.A., Souza, W.M., Evangelista, S., Santos, A.G., Malavolta, A.T., Vales, L.F., Segoria, D., Santos, F.S., Candeloro, L., Almeida, M.R., Yasuoka, F.M.M., Modugno, R.G., Cartolano, R., Barbalho, S., Santos, P.A., Rebolho, D., Otoboni, J.A., Correa, Y., Stefani, M.A. and Castro Neto, J.C., 2010, "The Advanced Wide Field Imaging Camera (AWFI) for the Amazonia 1 Brazilian Satellite", International Conference on Space Optics (ICSO), Rhodes, Greece.

U.S. Department of Defense, 1982, "Test Requirements for Space Vehicles - MIL-STD-1540B”, U.S. Air Force, Washington, D.C., USA, pp.16-17. 